\title{
Interpretation of arm circumference as an indicator of nutritional status
}

\author{
IAN MCDOWELL AND FELICITY SAVAGE KING \\ Department of Epidemiology and Community Medicine, University of Ottawa, Canada, and \\ Tropical Child Health Unit, Institute of Child Health, London
}

SUMMARY Data from a longitudinal study of 1342 Zambian children aged between 0 and 60 months are used to derive reference standards for mid-upper arm circumference. To determine the sensitivity, specificity, and predictive value of the arm circumference measurement as an indicator of nutritional status, associations between arm circumference and other anthropometric and clinical indicators of nutritional status are presented. Although none of the anthropometric indices accurately reflects the clinical judgement of nutritional status, arm circumference is shown to be similar in accuracy to weight for age and to weight for length as an indicator of clinical malnutrition; it provides a viable alternative to these more cumbersome measurements for use in field surveys.

Stimulated by a 1969 conference, there has been an active debate over the use of mid-upper arm circumference (MUAC) as an indicator of the nutrit:onal status of children. ${ }^{2}$ The potential advantages of MUAC are clear: it is thought to measure wasting in which intervention could be useful, rather than stunting, in which it would not. ${ }^{34}$ As reference standards suggest that there is only a small increase in MUAC between ages 1 and 4 years (or even between 1 and 6), there may be no need to know the child's precise age. ${ }^{25}$ This opens the way for a very simple field test, and imaginative modifications to the already cheap and portable equipment have exploited this advantage. Notable among the modifications are the 'Shakir strip', ${ }^{6}$ which is a piece of $1 \mathrm{~cm}$ wide $x$-ray film with coloured bands to indicate nutritional status, and a bangle ${ }^{7}$ which fits only a malnourished arm. Arm circumference measurements have been used to survey large numbers of children in a short time, under adverse circumstances. $^{8}$

Several criticisms of the method have been made, questioning its validity as an indicator of nutritional status. ${ }^{9} 10$ The most widely used reference standards were based on measurements of Polish children, ${ }^{2}$ and may be unsuitable for other populations. ${ }^{11}$ The age-independence of MUAC has also been disputed. ${ }^{12}$ Furthermore, although correlations between +0.70 and 0.90 have been reported between MUAC and weight for age, ${ }^{5} 813$ the two indices may disagree over which children are at risk. ${ }^{9}$ The agreement between MUAC and weight for age appears to vary from continent to continent ${ }^{13}$; and it is unclear which may prove the most adequate predictor of clinically diagnosed malnutrition. Very few prospective studies of the predictive power of either index have been carried out. ${ }^{14} 15$

That there are methodological problems in evaluating MUAC is clear; there is disagreement over whether it reflects weight for age or whether it can indicate clinical malnutrition directly; the method may be more useful in specific age-groups than in all children between 1 and 6 years. ${ }^{4510}$

Ultimately, three things are needed: firstly, standards of MUAC appropriate for children in developing countries; secondly, prospective studies of the value of MUAC for predicting frank malnutrition, increased susceptibility to infection, or death. Thirdly, while awaiting such studies, we may examine the sensitivity and specificity of arm circumference as a nutritional indicator, and in particular whether validity is sacrificed by using a single cut-off point across the age range. This paper is a contribution towards the first and third of these needs. An attempt is made to derive reference standards of MUAC from a study of children aged between 1 and 60 months in Lusaka, Zambia. The association between MUAC and weight and length data is examined, and their validity as indicators of clinical malnutrition are compared. The adequacy of a single arm circumference figure as a cut-off point between well-nourished and 'at risk' children between 12 and 60 months is discussed.

\section{Method}

Altogether 1342 children aged between 1 and 60 
months took part in a follow-up study from 1970 to 1972 in two contrasting suburbs of Lusaka, one an authorised municipal suburb, and the other an unauthorised squatter settlement. The children came from 589 families, and extensive information on each family was collected. The principal aims of the study were to examine the social and environmental bases for the children's growth patterns and illnesses, and to see how appropriately the health services catered for their needs. A supplementary objective was to evaluate the use of the left MUAC measurement as a public health index of nutritional status in a community where kwashiorkor was present, and where it was possible to establish age accurately.

In the two suburbs sample areas were defined geographically, and a census of children under 5 years was made in each. Only families with at least one child under 5 were included in the study. The families were visited at home at 6-monthly intervals by a paediatrician (FSK) and a research assistant. At each visit the children were weighed and measured, and nutritional and medical histories were taken. Other information was collected on separate occasions between the clinical visits, so that each family was visited about every 2 months by someone. The intention was to weigh and measure each child four times over 2 years, but in many cases this was not achieved owing to death of the child, departure of the family, or because another child had been born into the family. Although strenuous attempts were made to locate absent children, there were fewer than four sets of anthropometric and health data for many of them. There were 3294 sets of anthropometric observations in all; an average of 2.5 for each child. For the analysis presented here, measurements on each child made on different occasions were treated as independent observations.

Age was determined by asking the mother both the child's age and his date of birth. A male research assistant made contact with each father, and asked to see any written record of the birth; a record was found to exist for most of the children. If there was no record, stated age was checked against as much other information as possible (interval between pregnancies, season of birth, etc.).

Measurements of arm circumference in centimetres were made on the mid-upper left arm, using a non-stretch tape measure. ${ }^{3}$ Supine length was measured for children of all ages, using a locally made wooden board with a fixed foot piece and movable head piece. It was not possible to carry a stadiometer. Weight (in $\mathrm{kg}$ ) was measured using a Salter hanging spring balance, the accuracy of which was checked every week. The raw anthropometric data comprised weight, length, and arm circumference measurements. In addition, index values were calculated by expressing the raw figures as a percentage of the reference standards by sex and age to the nearest month. The resulting indices are referred to as 'weight for age', 'length for age', 'arm circumference for age', and 'weight for height'. Arm circumference standards were taken from Burgess and Burgess, ${ }^{2}$ and data for each month of age interpolated from their figures. Harvard and Boston standards were used for the other indices.

Children were classified as clinically malnourished or not malnourished at each visit. The diagnosis of clinical malnutrition was made on the grounds of the appearance of the child naked, before measuring. Thinness, body proportions, poor hair, skin pallor, oedema, and inactivity were the main factors contributing to this impression.

\section{Results}

Altogether 1716 arm circumference measurements were obtained for boys, and 1578 for girls aged 1 to 60 months. This gave an average of $28 \cdot 6$ observations each month per age group for the boys and $26 \cdot 2$ for the girls.

Arm circumference reference standards. To show how the Zambian data compared with the Polish standards, ${ }^{2}$ median arm circumferences were calculated using all observations, by monthly age group and sex. The resulting curves differ partly because of a flattening of the Zambian curve between ages 10 and 20 months, and partly because the curve is lower at all ages from 2 months onwards (Fig. 1). In drawing the Figure, the curve was smoothed by age.

Seventy-five of the 1342 children were diagnosed clinically as having malnutrition during the survey, while for a further 23 children, the mother described

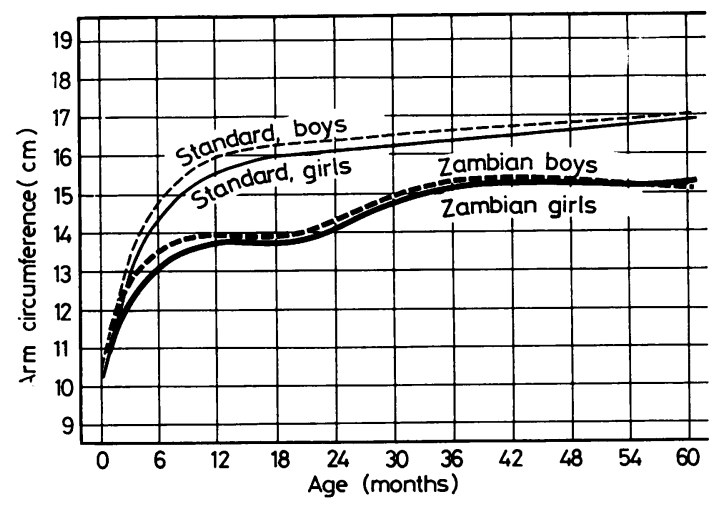

Fig. 1 Arm circumference of Zambian girls and boys, by age, compared with Polish standards. 50th centile (median) values shown in $\mathrm{cm}$. 
malnutrition before the survey, or during a prolonged absence between measurements. To calculate reference standards based on these data, all children suspected or known to have been malnourished were excluded from the sample. Measurements of children who were suffering from diarrhoea, measles, or 'fever' at the time of measurement were also excluded, so as to provide standards based on an arguably healthy subset of the sample.

To calculate centile values based on these data, boys and girls were grouped into broader age categories. Raw centile reference values are shown in Table 1; curves slightly smoothed are shown for each gender in Figs 2 and 3.

On the assumption that certain of the irregularities in the raw data were caused by the low numbers of children, and by the arbitrary age groupings used, reference values for clinical application should be derived from Figs 2 and 3.

To assess whether the flattening of the curve between 10 and 20 months was due to inclusion of subclinically malnourished children, separate curves

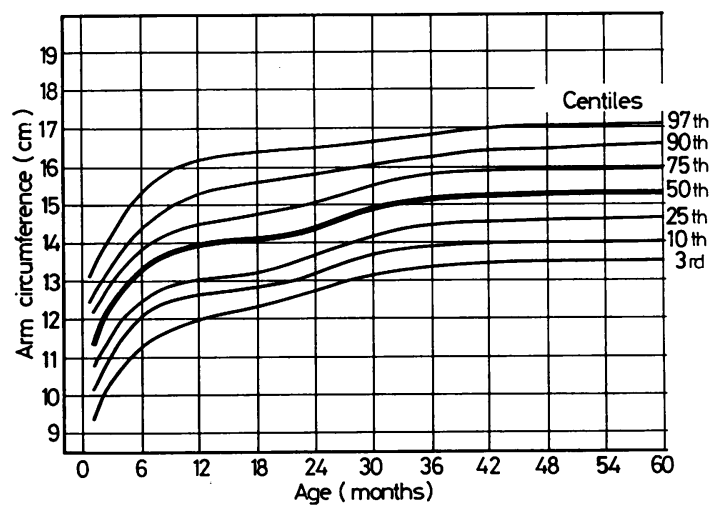

Fig. 2 Arm circumference of healthy Zambian girls by age, showing centiles.

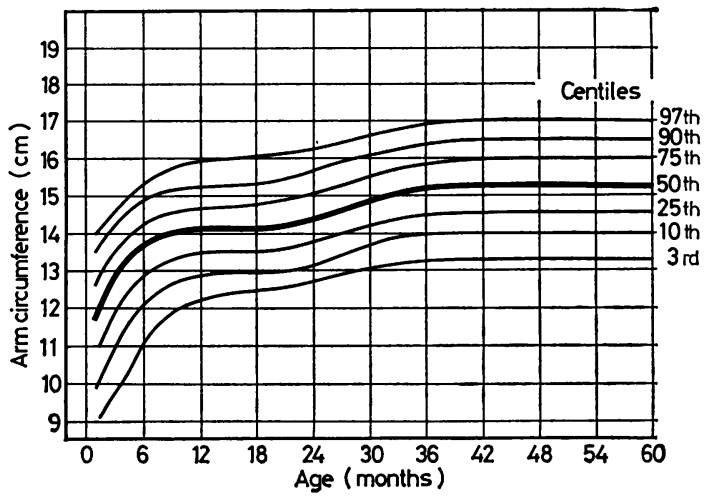

Fig. 3 Arm circumference of healthy Zambian boys, by age, showing centiles.

were drawn for children whose weight for age was above $80 \%$ of the Boston standard. Flattening of the MUAC curve could still be seen for these cases.

Interpretation of arm circumference as a nutritional indicator. Arm circumference is proposed as an indicator of nutritional status for children over age 12 months; until 48 or 60 months age independence of the indicator is claimed. ${ }^{2} 35$ There were 2543 sets of observations on children aged between 12 and 60 months; Table 2 shows the associations among arm circumference, weight, and length for these children.

The raw weight and length intercorrelate highly; arm circumference is associated with these, but less strongly. Weight and length also correlate strongly with age; as expected arm circumference shows a lower association. The index values (weight for age, length for age, and arm circumference for age) correlate less strongly with age, although they are not independent of it. This is owing to a dip in the mean values for these indices in children between 12 and 24 months; equivalent figures computed across all ages 1-60 show a negligible association with age.

Table 1 Selected centile values for arm circumference. Healthy Zambian children aged 0 to 60 months

\begin{tabular}{|c|c|c|c|c|c|c|c|c|c|c|c|c|c|c|c|c|}
\hline \multirow{2}{*}{$\begin{array}{l}\text { Girls } \\
n\end{array}$} & \multicolumn{7}{|c|}{ Centiles $(\mathrm{cm})$} & \multirow{2}{*}{$\begin{array}{l}\text { Ages of } \\
\text { boys and } \\
\text { girls (months) }\end{array}$} & \multirow{2}{*}{$\begin{array}{l}\text { Boys } \\
n\end{array}$} & \multicolumn{7}{|c|}{ Centiles $(\mathrm{cm})$} \\
\hline & $3 r d$ & $10 t h$ & $25 t h$ & $50 t h$ & $75 t h$ & 90th & $97 t h$ & & & $3 r d$ & 10th & $25 t h$ & $50 t h$ & $75 t h$ & $90 t h$ & 97th \\
\hline $\begin{array}{r}79 \\
89 \\
68 \\
55 \\
120 \\
107 \\
115 \\
108 \\
125 \\
116 \\
117 \\
98\end{array}$ & $\begin{array}{l}9 \cdot 6 \\
10 \cdot 5 \\
11 \cdot 9 \\
11 \cdot 9 \\
11 \cdot 7 \\
12 \cdot 6 \\
12 \cdot 5 \\
13 \cdot 25 \\
13 \cdot 4 \\
13 \cdot 45 \\
13 \cdot 75 \\
13 \cdot 6\end{array}$ & $\begin{array}{l}10 \cdot 3 \\
11 \cdot 85 \\
12.45 \\
12.4 \\
12.7 \\
12.75 \\
13.4 \\
13 \cdot 6 \\
13.9 \\
13.95 \\
14 \cdot 0 \\
14 \cdot 1\end{array}$ & $\begin{array}{l}10 \cdot 95 \\
12 \cdot 3 \\
12 \cdot 9 \\
12 \cdot 85 \\
13 \cdot 1 \\
13 \cdot 45 \\
13 \cdot 95 \\
14 \cdot 4 \\
14 \cdot 4 \\
14 \cdot 6 \\
14 \cdot 55 \\
14 \cdot 45\end{array}$ & $\begin{array}{l}11 \cdot 7 \\
12 \cdot 7 \\
13 \cdot 65 \\
13 \cdot 4 \\
14 \cdot 0 \\
14 \cdot 1 \\
14 \cdot 7 \\
15 \cdot 0 \\
15 \cdot 2 \\
15 \cdot 25 \\
15 \cdot 2 \\
15 \cdot 1\end{array}$ & $\begin{array}{l}12 \cdot 35 \\
13 \cdot 6 \\
14 \cdot 3 \\
14 \cdot 35 \\
14 \cdot 6 \\
14 \cdot 8 \\
15 \cdot 3 \\
15 \cdot 7 \\
15 \cdot 7 \\
15 \cdot 9 \\
15 \cdot 95 \\
16 \cdot 0\end{array}$ & $\begin{array}{l}12 \cdot 95 \\
14 \cdot 2 \\
15 \cdot 5 \\
15 \cdot 0 \\
15 \cdot 4 \\
15 \cdot 7 \\
15 \cdot 9 \\
16 \cdot 2 \\
16 \cdot 3 \\
16 \cdot 45 \\
16 \cdot 7 \\
16 \cdot 6\end{array}$ & $\begin{array}{l}13 \cdot 45 \\
15 \cdot 2 \\
15 \cdot 9 \\
15 \cdot 6 \\
16 \cdot 7 \\
16 \cdot 2 \\
16 \cdot 7 \\
17 \cdot 0 \\
16 \cdot 7 \\
17 \cdot 0 \\
17 \cdot 1 \\
17 \cdot 1\end{array}$ & $\begin{array}{r}0-2 \cdot 9 \\
3-5 \cdot 9 \\
6-8 \cdot 9 \\
9-11 \cdot 9 \\
12-17 \cdot 9 \\
18-23 \cdot 9 \\
24-29 \cdot 9 \\
30-35 \cdot 9 \\
36-41 \cdot 9 \\
42-47 \cdot 9 \\
48-53 \cdot 9 \\
54-59 \cdot 9\end{array}$ & $\begin{array}{r}88 \\
74 \\
73 \\
51 \\
117 \\
118 \\
134 \\
116 \\
139 \\
120 \\
112 \\
109\end{array}$ & $\begin{array}{l}9 \cdot 2 \\
10 \cdot 6 \\
11 \cdot 95 \\
11 \cdot 5 \\
12 \cdot 3 \\
12 \cdot 55 \\
13 \cdot 2 \\
13 \cdot 6 \\
13 \cdot 0 \\
13 \cdot 3 \\
13 \cdot 1 \\
13 \cdot 2\end{array}$ & $\begin{array}{l}10.1 \\
11.9 \\
12.4 \\
12.85 \\
12.85 \\
13.0 \\
13.5 \\
14.05 \\
13.6 \\
13.9 \\
13.7 \\
13.9\end{array}$ & $\begin{array}{l}11 \cdot 1 \\
12 \cdot 6 \\
13 \cdot 1 \\
13 \cdot 4 \\
13 \cdot 4 \\
13 \cdot 7 \\
14 \cdot 0 \\
14 \cdot 5 \\
14 \cdot 45 \\
14 \cdot 5 \\
14 \cdot 55 \\
14 \cdot 35\end{array}$ & $\begin{array}{l}12 \cdot 1 \\
13 \cdot 5 \\
13 \cdot 9 \\
14 \cdot 0 \\
14 \cdot 0 \\
14 \cdot 2 \\
14 \cdot 7 \\
15 \cdot 1 \\
15 \cdot 3 \\
15 \cdot 2 \\
15 \cdot 1 \\
15 \cdot 3\end{array}$ & $\begin{array}{l}12 \cdot 9 \\
14 \cdot 1 \\
14 \cdot 4 \\
14 \cdot 6 \\
14 \cdot 65 \\
14.95 \\
15 \cdot 2 \\
15 \cdot 7 \\
15 \cdot 95 \\
15 \cdot 95 \\
15.95 \\
16 \cdot 05\end{array}$ & $\begin{array}{l}13 \cdot 9 \\
14 \cdot 7 \\
15 \cdot 15 \\
15 \cdot 25 \\
15 \cdot 3 \\
15 \cdot 5 \\
15 \cdot 9 \\
16 \cdot 25 \\
16 \cdot 5 \\
16 \cdot 45 \\
16 \cdot 5 \\
16 \cdot 45\end{array}$ & $\begin{array}{l}14 \cdot 2 \\
15 \cdot 1 \\
15 \cdot 5 \\
16 \cdot 1 \\
16 \cdot 0 \\
16 \cdot 2 \\
16 \cdot 4 \\
16 \cdot 8 \\
17 \cdot 2 \\
17 \cdot 0 \\
17 \cdot 0 \\
16 \cdot 8\end{array}$ \\
\hline
\end{tabular}


Table 2 Pearson correlations between selected anthropometric measurements, and age. Zambian children, both genders combined, aged 12 to 60 months; 2543 observations

\begin{tabular}{|c|c|c|c|c|c|c|c|}
\hline & Weight & Length & $\begin{array}{l}\text { Arm } \\
\text { circumference } \\
(M U A C)\end{array}$ & $\begin{array}{l}\text { Weight } \\
\text { for age }\end{array}$ & $\begin{array}{l}\text { Length } \\
\text { for age }\end{array}$ & $\begin{array}{l}\text { Arm } \\
\text { circumference } \\
\text { for age }\end{array}$ & $\begin{array}{l}\text { Weight } \\
\text { for length }\end{array}$ \\
\hline $\begin{array}{l}\text { Length } \\
\text { Arm circumference (MUAC) } \\
\text { Weight for age* } \\
\text { Length for age* } \\
\text { Arm circumference for age } \dagger \\
\text { Weight for length } \ddagger \\
\text { Age }\end{array}$ & $\begin{array}{l}0.93 \\
0.73 \\
0.68 \\
0.45 \\
0.60 \\
0.55 \\
0.85\end{array}$ & $\begin{array}{l}0.53 \\
0.45 \\
0.47 \\
0.37 \\
0.22 \\
0.92\end{array}$ & $\begin{array}{l}0.76 \\
0.32 \\
0.98 \\
0.78 \\
0.44\end{array}$ & $\begin{array}{l}0 \cdot 70 \\
0 \cdot 78 \\
0 \cdot 76 \\
0 \cdot 20\end{array}$ & $\begin{array}{l}0 \cdot 33 \\
0 \cdot 10 \\
0 \cdot 12\end{array}$ & $\begin{array}{l}0.79 \\
0.26\end{array}$ & $0 \cdot 20$ \\
\hline
\end{tabular}

* Using Harvard and Boston reference standards. † Standards derived from Burgess and Burgess, ${ }^{2} \quad \ddagger$ Standards derived from Jelliffe. ${ }^{3}$

Arm circumference correlates more highly with weight $(0.73)$ than it does with length $(0.53)$; it also correlates more strongly $(0.78)$ with weight for length than does weight $(0 \cdot 55)$. These findings suggest that MUAC reflects wasting rather than stunting; and it is more independent of age than are weight or length.

The sensitivity, specificity, and predictive value ${ }^{16}$ of arm circumference as an indicator of clinically diagnosed malnutrition were compared with results for the other anthropometric indices. Because the prevalence of malnutrition is low in children over 36 months, the calculations were made for two age groups: $12-60$ and $12-36$ months. The results were little different for the two age groups; the results for the full 12-60 age range are presented. Of the 2543 observations, 100 were on clinically malnourished children. As the prime requirement of a screening test is that it should correctly identify the majority of malnourished cases, even at the expense of identifying a number of 'false positives', the cut-off point for each of the indices was fixed to provide a sensitivity

Table 3 Specificity and positive predictive value results for arm circumference (single cut-off point and for age), weight for age, and weight for height as indicators of clinically diagnosed malnutrition, at a sensitivity level of $95 \%$. Zambian children, 12-60 months; 2543 observations

\begin{tabular}{|c|c|c|c|c|}
\hline & $\begin{array}{l}\text { Cut-off } \\
\text { point* }\end{array}$ & Specificity & $\begin{array}{l}\text { False- } \\
\text { positive } \\
\text { rate }(\%)\end{array}$ & $\begin{array}{l}\text { Positive } \\
\text { predictive } \\
\text { value }(\%)\end{array}$ \\
\hline $\begin{array}{l}\text { Arm circumference } \\
\text { (single cut-off point) }\end{array}$ & $15 \mathrm{~cm}$ & 0.44 & 56 & $6 \cdot 5$ \\
\hline $\begin{array}{l}\text { Arm circumference for } \\
\text { age (Polish standard) }\end{array}$ & $\begin{array}{l}90 \% \\
\text { standard }\end{array}$ & 0.42 & 58 & $6 \cdot 5$ \\
\hline $\begin{array}{l}\text { Arm circumference for } \\
\text { age (Zambian } \\
\text { standard) }\end{array}$ & $\begin{array}{l}100 \% \\
\text { standard }\end{array}$ & 0.43 & 57 & $6 \cdot 5$ \\
\hline Weight for age & $\begin{array}{l}89 \% \\
\text { standard }\end{array}$ & 0.36 & 64 & $5 \cdot 7$ \\
\hline Weight for length & $\begin{array}{l}100 \% \\
\text { standard }\end{array}$ & $0 \cdot 30$ & 70 & $5 \cdot 0$ \\
\hline
\end{tabular}

* Each cut-off point was chosen so that $95 \%$ of all malnourished children would be identified as such by the index. of $95 \%$ (that is, only $5 \%$ of malnourished cases would be missed). Table 3 shows the corresponding specificity figures, and the cut-off point at which $95 \%$ of all the malnourished children would be selected. The false-positive rate suggests the proportion of children not clinically malnourished who would be picked out. The positive predictive value shows the likelihood that a low-scoring child would be clinically malnourished. For all methods the specificity and predictive value appear low; it may be that many children were undernourished without exhibiting clinical malnutrition. Three ways of calculating arm circumference indices are presented: using a single cut-off point, using Polish, or the Zambian standards presented above. Each method gave comparable results, and provided slightly better indicators of clinical nutritional status than did weight for age or weight for length.

\section{Discussion}

If the Zambian arm circumference data and the Polish standards are compared, the general lowering of the Zambian curve, and the flattening of it in the second year are striking. The flattening of the arm circumference curve persisted even when only those children whose weight for age was above $80 \%$ of the standard were considered. Similar results have been obtained elsewhere, ${ }^{41217}$ and were noted in Uganda for weight and height. ${ }^{18}$ Flattening of the growth curves may occur because many children are undernourished during the second year; this may be an almost physiological effect of weaning with certain diets. It is not known whether the temporary flattening is harmful to previously well-nourished children.

If the Polish arm circumference standard is used, individual data should be expressed as percentages of the median, because in a developing country many children fall below the lowest centiles. An advantage of the Zambian data (Figs 2 and 3) is that individual children can be referred to the centiles. The spread of the centiles is such that roughly a $0.5 \mathrm{~cm}$ 
difference in arm circumference separates the 3rd, 10 th, 25th, and 50th centiles; an accuracy of measurement within $0.5 \mathrm{~cm}$ is attainable under field conditions.

This report differs from several others in describing the validity of MUAC by relating it to a clinical diagnosis of malnutrition, as well as by comparing it with weight for age. Neither clinical judgement nor anthropometric measurements alone is likely to provide an adequate indication of the elusive quality 'nutritional status'. Shakir et al. ${ }^{\mathbf{1 9}}$ noted that from clinical judgements, $30 \%$ of the children whose weight fell below $80 \%$ of standard were not identified as undernourished; the discrepancy occurred mainly among children between 70 and $80 \%$ of standard. Conversely, the present study included several children with clinical malnutrition who were above $85 \%$ weight for age. The explanation of such cases falls beyond the scope of this report; it is sufficient to note that we lack a reliable standard against which finally to evaluate any anthropometric indicators of nutritional status.

The validity results shown in Table 3 suggest that all the anthropometric indices performed poorly as indicators of clinically diagnosed malnutrition. While the specificity results can be greatly improved by altering the cut-off point chosen (and thereby sacrificing sensitivity), the positive predictive value remains low, because of the low prevalence of malnutrition in this sample $(3.9 \%)$. With this prevalence, each of the anthropometric indices would identify about 14 false-positives for each malnourished child correctly classified. Although the raw MUAC figures obtained in this study were not independent of age between 20 and 30 months, a single cut-off value of MUAC proved equally valid as an indicator of poor nutritional status as did the use of reference standards. The cut-off point of $15 \mathrm{~cm}$ identified here is higher than that derived in other studies: Farquharson suggested $14.0 \mathrm{~cm},{ }^{17}$ while Shakir and Morley found that most children above $13.5 \mathrm{~cm}$ were normal. ${ }^{56}$ Anderson ${ }^{13}$ noted however, that a cut-off of $13.5 \mathrm{~cm}$ was too low. The appropriate cut-off point to use may differ according to country.

Although the use of the Morley-Shakir measuring strip will identify a large number of 'normal' children among the malnourished, its simplicity of use commends it above the more complex indices based on weight and length which are not shown by the present data to provide superior information.

Support for this project was provided by the Nuffield Foundation, London, the University of Zambia, and the Permanent Secretary for Health, Zambia.

\section{References}

1 Jelliffe D B, Jelliffe E F P. The arm circumference as a public health index of protein-calorie malnutrition of early childhood. Monograph 8. J Trop Pediatr 1969; 15: $177-88$.

2 Burgess H J L, Burgess A P. A modified standard for mid-upper arm circumference in young children. Monograph 8. J Trop Pediatr 1969; 15: 189-92.

3 Jelliffe D B. The assessment of the nutritional status of the community. Monograph No 53. Geneva: WHO, 1966.

4 Zeitlin M F. An age-independent screening index for preschool nutrition interventions. PhD thesis. Massachusetts Institute of Technology, 1977.

5 Shakir A. Arm circumference in the surveillance of protein-calorie malnutrition in Baghdad. Am J Clin Nutr 1975; 28: 661-5.

6 Shakir A, Morley D. Letter: Measuring malnutrition. Lancet 1974; i: 758-9.

7 Shah P M, Khare R D, Rane A V, Bhalerao V Y. The bangle as a tool for assessing malnutrition of under-sixes. Indian J Nutr Dietet 1976; 13: 148-52.

8 Loewenstein M S, Phillips J F. Evaluation of arm circumference measurement for determining nutritional status of children and its use in an acute epidemic of malnutrition: Owerri, Nigeria, following the Nigerian Civil War. Am J Clin Nutr 1973; 26: 226-33.

9 Ramachandran K, Parmar B S, Jain J K, Tandon B N, Gandhi P C. Limitations of film strip and bangle test for identification of malnourished children. Am J Clin Nutr 1978; 31 : 1469-72.

10 Vijayaraghaven K, Sastry J G. The efficacy of arm circumference as a substitute for weight in assessment of protein-calorie malnutrition. Ann Hum Biol 1976; 3: 229-33.

11 Burgert S L, Anderson C F. An evaluation of upper arm measurements used in nutritional assessment. Am J Clin Nutr 1979; 32: 2136-42.

12 Martorell R, Yarbrough C, Lechtig A, Delgado E, Klein $\mathbf{R}$ E. Upper arm anthropometric indicators of nutritional status. Am J Clin Nutr 1976; 29: 46-53.

13 Anderson M A. Comparison of anthropometric measures of nutritional status in preschool children in five developing countries. Am J Clin Nutr 1979; 32: 2339-45.

14 Sommer A, Loewenstein M S. Nutritional status and mortality: a prospective validation of the QUAC stick. Am J Clin Nutr 1975; 28: 287-92.

15 Kielmann A A, McCord C. Weight-for-age as an index of risk of death in children. Lancet $1978 ;$ i: 1247-50.

16 Habicht J P. Some characteristics of indicators of nutritional status for use in screening and surveillance. Am J Clin Nutr 1980; 33: 531-5.

17 Farquharson S M. Growth patterns and nutrition in Nepali children. Arch Dis Child 1976; 51: 3-12.

18 Rutishauser I H E. Heights and weights of middle-class Baganda children. Lancet 1965; ii: 565-7.

19 Shakir A, Demarchi M, El-Milli N. Pattern of proteincalorie malnutrition in young children attending an outpatient clinic in Baghdad. Lancet 1972; ii: 143-6.

Correspondence to Dr I McDowell, Department of Epidemiology and Community Medicine, University of Ottawa, 1461 Heron, K1V 6A6, Ottawa, Canada.

Received 28 May 1981 